\title{
Adrenal Morphology as an Indicator of Long-Term Disease Control in Adults with Classic 21-Hydroxylase Deficiency
}

\author{
Taek Min Kim ${ }^{1, *}$, Jung Hee Kim²,*, Han Na Jang ${ }^{2}$, Man Ho Choi ${ }^{3}$, Jeong Yeon Cho ${ }^{1,4}$, Sang Youn Kim ${ }^{1}$ \\ Departments of ${ }^{1}$ Radiology, ${ }^{2}$ Internal Medicine, Seoul National University Hospital, Seoul National University College of \\ Medicine; ${ }^{3}$ Molecular Recognition Research Center, Korea Institute of Science and Technology; ${ }^{4}$ Institute of Radiation \\ Medicine and Kidney Research Institute, Seoul National University Medical Research Center, Seoul, Korea
}

Background: Monitoring adults with classical 21-hydroxylase deficiency (21OHD) is challenging due to variation in clinical and laboratory settings. Moreover, guidelines for adrenal imaging in 21OHD are not yet available. We evaluated the relationship between adrenal morphology and disease control status in classical 21OHD.

Methods: This retrospective, cross-sectional study included 90 adult $21 \mathrm{OHD}$ patients and 270 age- and sex-matched healthy controls. We assessed adrenal volume, width, and tumor presence using abdominal computed tomography and evaluated correlations of adrenal volume and width with hormonal status. We investigated the diagnostic performance of adrenal volume and width for identifying well-controlled status in 21OHD patients (17 $\alpha$-hydroxyprogesterone [17-OHP] $<10 \mathrm{ng} / \mathrm{mL}$ ).

Results: The adrenal morphology of 21OHD patients showed hypertrophy (45.6\%), normal size (42.2\%), and hypotrophy (12.2\%). Adrenal tumors were detected in 12 patients (13.3\%). The adrenal volume and width of 21OHD patients were significantly larger than those of controls $(18.2 \pm 12.2 \mathrm{~mL}$ vs. $7.1 \pm 2.0 \mathrm{~mL}, 4.7 \pm 1.9 \mathrm{~mm}$ vs. $3.3 \pm 0.5 \mathrm{~mm}, P<0.001$ for both). The 17-OHP and androstenedione levels were highest in patients with adrenal hypertrophy, followed by those with normal adrenal glands and adrenal hypotrophy ( $P<0.05$ for both). Adrenal volume and width correlated positively with adrenocorticotropic hormone, 17-OHP, $11 \beta$-hydroxytestosterone, progesterone sulfate, and dehydroepiandrosterone sulfate in both sexes $(r=0.33-0.95, P<0.05$ for all). For identifying well-controlled patients, the optimal cut-off values of adrenal volume and width were $10.7 \mathrm{~mL}$ and $4 \mathrm{~mm}$, respectively (area under the curve, $0.82-0.88 ; P<0.001$ for both).

Conclusion: Adrenal volume and width may be reliable quantitative parameters for monitoring patients with classical $21 \mathrm{OHD}$.

Keywords: Adrenal hyperplasia, congenital; Adrenal cortex; Adrenal volume; Androgens

\section{INTRODUCTION}

Congenital adrenal hyperplasia is an autosomal recessive disease caused by impaired steroidogenesis, and 21-hydroxylase deficiency (21OHD) accounts for approximately $95 \%$ of cases [1]. Since adults with 210 HD exhibit a broad spectrum of enzyme deficiency and clinical features, it is challenging to achieve adrenal androgen suppression and optimal steroid re-
Received: 23 September 2021, Revised: 16 November 2021,

Accepted: 14 December 2021

Corresponding author: Sang Youn Kim

Department of Radiology, Seoul National University Hospital, Seoul National University College of Medicine, 101 Daehak-ro, Jongno-gu, Seoul 03080, Korea

Tel: +82-2-2072-2518, Fax: +82-2-747-5781, E-mail: iwishluv@empas.com

\section{Copyright $@ 2022$ Korean Endocrine Society}

This is an Open Access article distributed under the terms of the Creative Commons Attribution Non-Commercial License (https://creativecommons.org/ licenses/by-nc/4.0/) which permits unrestricted non-commercial use, distribution, and reproduction in any medium, provided the original work is properly cited.

*These authors contributed equally to this work. 
placement simultaneously. Undertreatment results in androgen excess and adrenal insufficiency, while overtreatment causes iatrogenic Cushing syndrome and metabolic syndrome, the components of which include obesity and hypertension [2,3]. Traditionally, 17 $\alpha$-hydroxyprogesterone (17-OHP) has been measured as the therapeutic indicator for hormone control. In recent studies, androstenedione, 21-deoxycortisol, and 11-oxygenated androgens have been recommended as reliable markers for disease control; however, these hormone measurements are not available in clinical practice [4]. Additionally, the optimal target levels of these hormones have not been established since the reference range and sampling time vary [4]. Thus, another marker for reflecting disease control is needed.

Adrenal volumetry has been used to evaluate the dimensions of normal adrenal glands and to characterize specific diseases that may affect the adrenal parenchyma [5-9]. Adrenal imaging is not routinely recommended in patients with $21 \mathrm{OHD}$ [4], but may be considered in patients with a long history of poor disease control, inconsistent therapy, or difficult-to-control disease as a rule of thumb [10]. Previous studies have investigated the correlation between adrenal volume and hormonal status $[11,12]$. However, the clinical significance of adrenal volume in patients with 21OHD has not been well demonstrated.

We compared the adrenal morphology, including limb width and volume, between classical 21OHD patients and healthy controls. Furthermore, we aimed to gather more evidence on the relationship between adrenal volume and biochemical parameters in patients with $21 \mathrm{OHD}$ and to evaluate the diagnostic value of adrenal volume as a long-term disease control marker.

\section{METHODS}

\section{Study population}

The Institutional Review Board of Seoul National University Hospital approved this retrospective study and waived the requirement for informed consent (IRB no.: H-2004-147-1118). Between November 2016 and March 2021, we identified 308 patients with 21OHD who visited the endocrine clinic of our center. Among these, 95 patients fulfilled the following inclusion criteria: (1) age >18 years; (2) underwent abdominal computed tomography (CT) for adrenal imaging; and (3) underwent hormonal evaluation on the same day as the CT scan. We excluded three patients with non-classical 21OHD and two patients who underwent unilateral adrenalectomy. This study included a final total of 90 patients (44 men and 46 women; mean age, $29.7 \pm 7.9$ years).
For comparisons of adrenal morphology and volume, this study included 270 age- and sex-matched controls (135 men and 135 women with a mean age of $31.7 \pm 3.9$ years) who underwent abdominal CT for health screening. We excluded patients with adrenal masses or any known endocrine diseases that might affect their adrenal glands.

\section{Clinical and biochemical data}

We reviewed each patient's electronic medical records and retrieved data from the visit for $\mathrm{CT}$ imaging. The body mass index (BMI) was defined as body weight divided by height squared $\left(\mathrm{kg} / \mathrm{m}^{2}\right)$. We measured blood pressure using an automated technique in a seated position after a 20 -minute rest.

We also assessed each patient's current glucocorticoid and fludrocortisone regimen. The daily glucocorticoid dose equivalents were calculated as follows: hydrocortisone, 1; prednisolone/prednisone, 4; and dexamethasone, 70 [13]. Glucocorticoid dose equivalents and the fludrocortisone dose were divided by body surface area (BSA) for normalization.

Morning fasting blood samples for laboratory tests were drawn before patients took steroid medications. Laboratory tests included plasma adrenocorticotropic hormone (ACTH), 17 OHP, androstenedione, 11 $\beta$-hydroxytestosterone (11 $\beta$-OHT), $11 \beta$-hydroxyandrostenedione (11 $\beta$-OHA), testosterone, progesterone sulfate (Preg-S), total testosterone, and plasma renin activity. We categorized 21OHD patients into well-controlled and poorly-controlled groups according to serum 17-OHP levels [4], using a 17-OHP level lower than $10 \mathrm{ng} / \mathrm{mL}$ as a cut-off for the well-controlled group corresponding to a level two-fold higher than the upper normal limit [3].

We included obesity, hyperglycemia, hypertension, and dyslipidemia as metabolic morbidities, which were modified from the harmonizing criteria of metabolic syndrome [14]. The definition of each metabolic morbidity is described in the supplementary materials.

\section{CT protocol}

All patients with 21OHD underwent either non-contrast $(n=83)$ or contrast-enhanced abdominal CT $(n=7)$ using multi-detector CT scanners (64 to 128 channels). In the control group, all patients underwent contrast-enhanced abdominal CT $(n=270)$. CT scans were performed in the supine position with a scan range from the top of the diaphragm to the inferior margin of the symphysis pubis. All scans were acquired in a single breath-hold to minimize motion and misregistration artifacts. The detailed settings were as follows: collimation, $64 \times 0.625 \mathrm{~mm}$, or $128 \times 0.6$ 
$\mathrm{mm}$; gantry rotation time, 0.5 second; pitch, 0.891 or 0.65 ; slice thickness, $3 \mathrm{~mm}$; reconstruction interval, $3 \mathrm{~mm}$; and matrix, $512 \times 512$.

Images were acquired using 80 to $120 \mathrm{kVp}$ tube energy and automatic tube current modulation technology available for each vendor (Care Dose 4D, Siemens Medical Solutions, Erlangen, Germany; Dose Right and Tube Current Modulation, Philips Medical Systems, Best, The Netherlands; or AutomA, GE Medical Systems, Milwaukee, WI, USA). For contrast-enhanced CT, portal phase images were obtained 70 seconds after administering the contrast medium. Iodinated contrast medium at a concentration of $350 \mathrm{mgI} / \mathrm{mL}$ was administered into the peripheral vein of the upper extremity via an automatic power injector at a total dosage of $1.5 \mathrm{~mL} / \mathrm{kg}$ over 30 seconds.

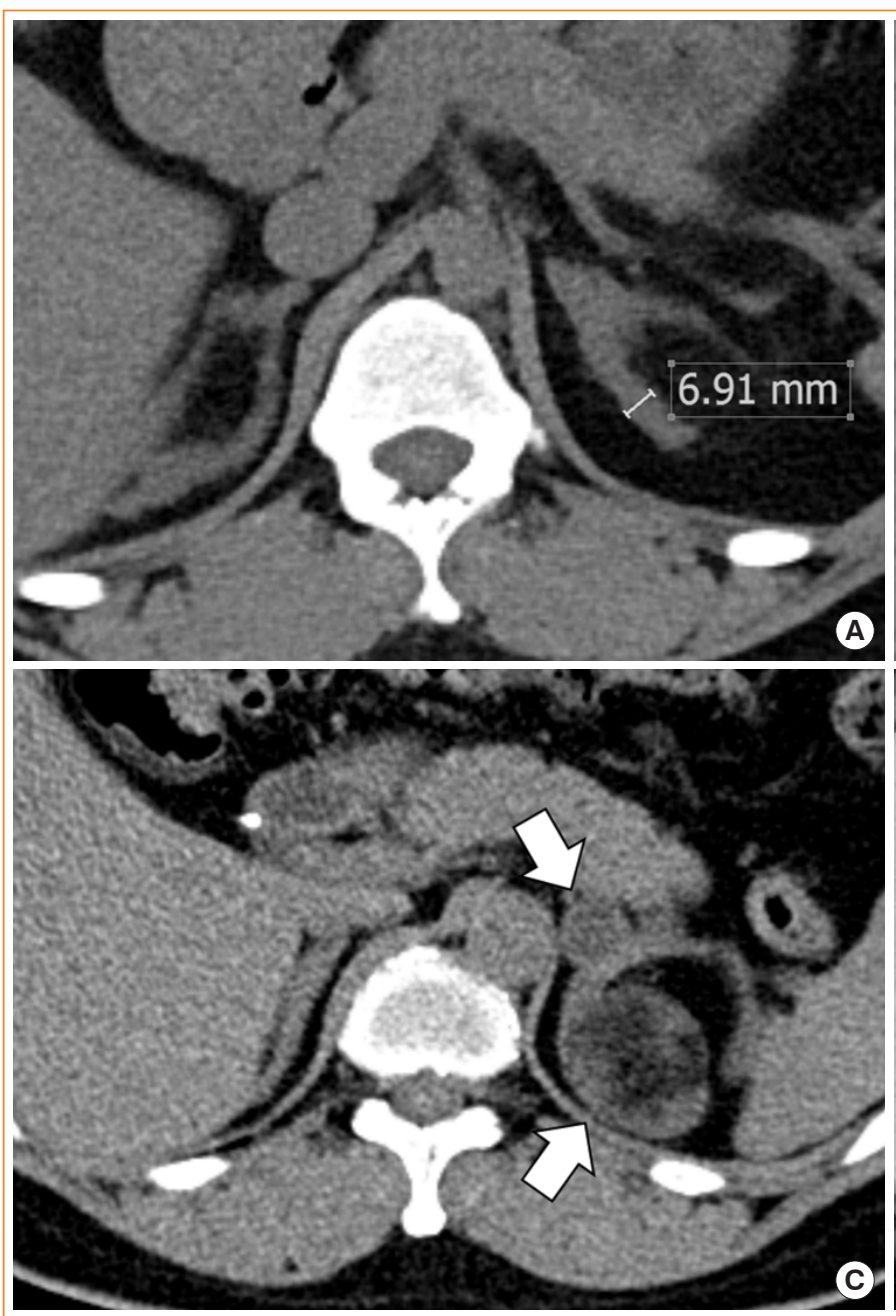

\section{Imaging analysis}

Two radiologists (T.M.K. and S.Y.K. with 6 and 16 years of genitourinary imaging experience, respectively) who were blinded to the related clinical information reviewed all CT images using a picture archiving and communication system (Infinitt, Infinitt Healthcare, Seoul, Korea).

Adrenal morphology was classified into hypertrophy, normal size, and hypotrophy according to a limb width $\geq 5 \mathrm{~mm}, \geq 2 \mathrm{~mm}$ and $<5 \mathrm{~mm}$, and $<2 \mathrm{~mm}$, respectively [8]. We measured the widths of the adrenal limbs at the widest part of the medial or lateral limbs perpendicular to the long axis of the limb in both adrenal glands and calculated the average of those measurements (Fig. 1). The readers carefully examined whether adrenal masses were present. A diagnosis of myelolipoma was considered when the readers detected gross fat inside the mass; other-

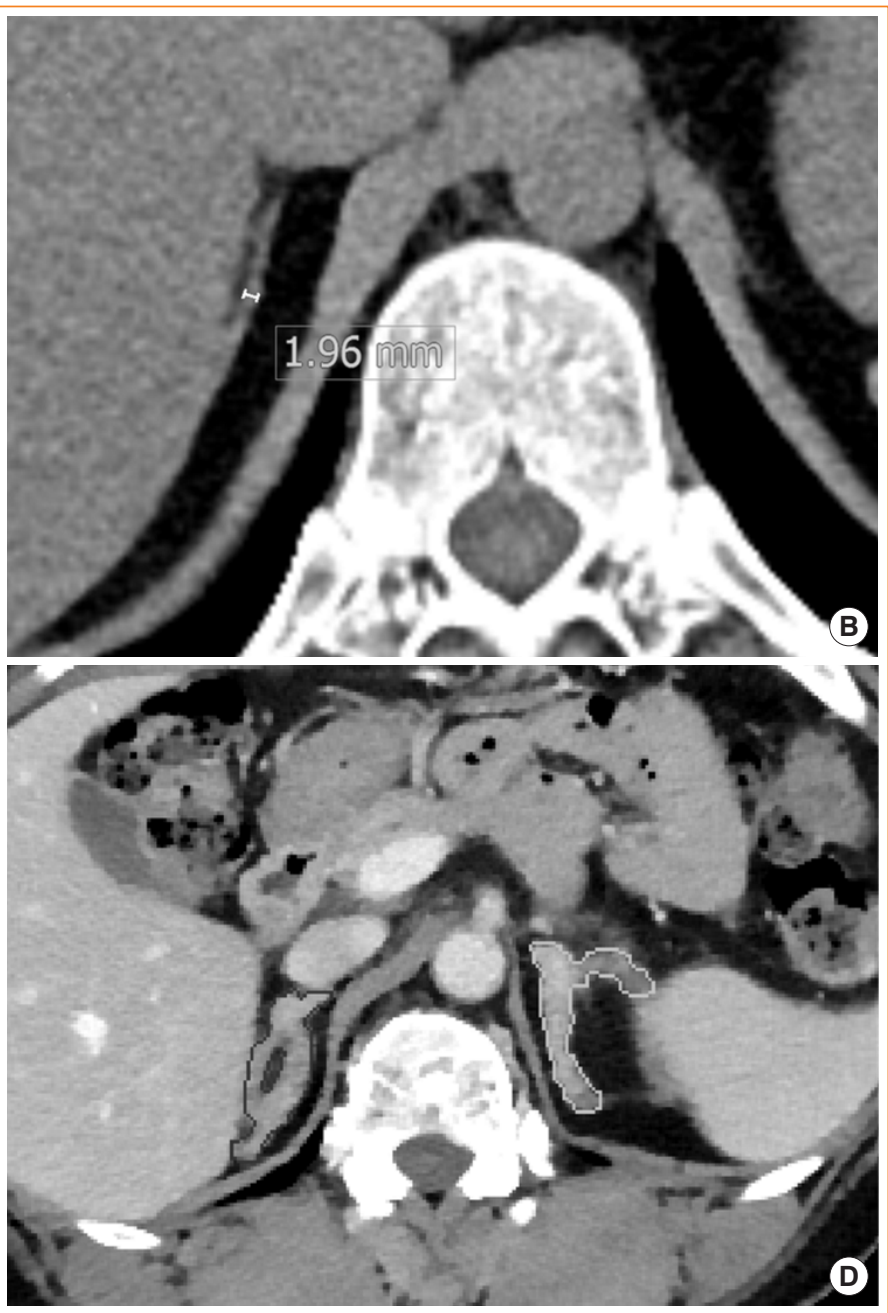

Fig. 1. Image analysis of patients with 21-hydroxylase deficiency (21OHD). We evaluated the adrenal morphology according to (A, B) limb width, (C) the presence of an adrenal mass (arrows), and (D) adrenal volume by manual segmentation. 
wise, it was considered an adenoma. In the case of a disagreement, a third radiologist (J.Y.C., 26 years of genitourinary imaging experience) who was also blinded to the patients' clinical information provided input.

For volumetric evaluation of the adrenal glands, one radiologist (T.M.K.) manually segmented the adrenal parenchyma on each side in axial CT images using commercially available software (MEDIP, Medical IP, Seoul, Korea). To make volumetric measurements, we manually drew the margin of the adrenal glands as close as possible to the surface of the gland to exclude adjacent fatty tissue, the liver, the inferior vena cava, spleen, and the pancreatic tail. We carefully avoided the tumor because we wanted to focus on the parenchymal volume. The total adrenal volume was computed by combining both sides of the adrenal parenchymal volume. We also segmented the adrenal tumors independently of the parenchyma, and the total tumor volume was calculated as the sum of all segmented tumors. All processes were performed in a standard abdominal window setting with a width of 300 and a level of 40 . To evaluate interobserver reliability, another radiologist (S.Y.K.) performed additional measurements of $90210 H D$ patients in the same manner.

Additionally, we performed whole-body composition analysis using a dedicated software program (DEEPCATCH, Medical IP). The software program provides fully automatic segmentation of body components with an average segmentation accuracy of 97\% compared with manual segmentation [15]. The L3 sectional area $\left(\mathrm{cm}^{2}\right)$ of skeletal muscle, abdominal visceral fat, and subcutaneous fat were automatically quantified. The total abdominal fat area was calculated by summing the abdominal visceral fat and subcutaneous fat areas. In addition, the waist circumference $(\mathrm{cm})$ was automatically measured in the level of the upper tip of the hip bone. One endocrinologist (H.N.J.) confirmed the results of automatic segmentation. We compared the body composition of the 21OHD patients between the wellcontrolled and poorly-controlled groups.

\section{Biochemical assays}

Plasma ACTH levels were measured using an immunoradiometric assay (Cisbio Bioassays, Saclay, France) with intra- and inter-assay coefficients of variation (CVs) of 3.7\% and $3.8 \%$. Radioimmunoassay (RIA) CT kits (Asbach Medical Products $\mathrm{GmbH}$, Obrigheim, Germany) were used to measure serum 17OHP and dehydroepiandrosterone sulfate (DHEA-S) levels. The intra- and inter-assay CVs for 17-OHP levels were 4.6\% and $7.7 \%$, respectively, and the respective CVs for DHEA-S levels were $3.6 \%$ and $6.5 \%$. Serum total testosterone levels were measured with a TESTO-CT2 kit (Cisbio Bioassays). The intra- and inter-assay CVs for total testosterone were $3.1 \%$ and $5.2 \%$, respectively. Plasma renin activity was gauged with a PRA RIA kit (TFB Inc., White Lake, MI, USA), with intra- and inter-assay $\mathrm{CVs}$ of $3.8 \%$ and $6.7 \%$, respectively.

Adrenal steroids, including androstenedione, $11 \beta-O H T$, $11 \beta$-OHA, testosterone, and Preg-S were quantitatively profiled by liquid chromatography-mass spectrometry (LC-MS), as described previously [16]. Based on individual serum concentrations, we also calculated the metabolic ratio of $11 \beta$-hydroxytestosterone to testosterone $(11 \beta-\mathrm{OHT} / \mathrm{T})$ to indicate testicular $11 \beta$-hydroxylase activity.

\section{Definition of metabolic morbidity}

Patients with a BMI $>25 \mathrm{~kg} / \mathrm{m}^{2}$ were considered obese. Hyperglycemia, which included diabetes mellitus and prediabetes, was defined as a hemoglobin A1c value $\geq 5.7 \%$, a fasting plasma glucose level $\geq 100 \mathrm{mg} / \mathrm{dL}$, or the use of any oral anti-diabetic drugs or insulin therapy. Hypertension was defined as a systolic blood pressure $\geq 130 \mathrm{~mm} \mathrm{Hg}$ and/or diastolic blood pressure $\geq 85 \mathrm{~mm} \mathrm{Hg}$ or the use of any antihypertensive medications. Dyslipidemia was defined as an abnormal lipid panel (total cholesterol $\geq 240 \mathrm{mg} / \mathrm{dL}$, low-density lipoprotein cholesterol $\geq 160 \mathrm{mg} / \mathrm{dL}$, triglycerides $\geq 150 \mathrm{mg} / \mathrm{dL}$, or high-density lipoprotein cholesterol $<40 \mathrm{mg} / \mathrm{dL}$ ) or the use of lipid-lowering agents.

\section{Statistical analysis}

For group comparisons, we used the Fisher exact test for categorical variables and the independent $t$ test or the Mann-Whitney $U$ test for continuous variables, as appropriate. The Kruskal-Wallis test with Conover post hoc analysis was performed to compare 17-OHP and androstenedione among the 21OHD patients according to adrenal morphology. We conducted subgroup analyses of the total adrenal volume according to the phenotype, regularity of menstruation, and presence of adrenal tumors. We used Spearman correlation coefficients for correlation analysis, for which non-normally distributed variables (all biochemical parameters and adrenal volume) were log-transformed.

A receiver operating characteristic analysis was performed to evaluate the diagnostic accuracy of adrenal volume and width for discriminating $210 \mathrm{HD}$ patients among the normal population, as well as to predict the well-controlled group and patients with at least one metabolic morbidity. Interobserver agreement was evaluated using the intraclass correlation coefficient (ICC), with ICC values of $<0.4,0.4-0.6,0.6-0.8$, and $>0.8$ interpreted 
as indicating poor, moderate, good, and excellent agreement, respectively. All statistical analyses were performed using SPSS version 25 (IBM, Armonk, NY, USA), and $P$ values of $<0.05$ were considered statistically significant.

\section{RESULTS}

\section{Patient characteristics}

Detailed information on the study group is summarized in Table
1. Forty-four (48.9\%) of the 90 patients with $210 H D$ were men. Forty-six patients (51.1\%) had the salt-wasting type of 21OHD, while 44 patients $(48.9 \%)$ had the simple virilizing type. There were no significant differences in the biochemical parameters and glucocorticoid doses between the salt-wasting and simple virilizing types (Table 2). All 90 patients were treated with prednisolone, two patients with hydrocortisone, and 55 with fludrocortisone. The median values of daily glucocorticoid dose/BSA and fludrocortisone dose/BSA were $17.5 \mathrm{mg} / \mathrm{m}^{2}$ (range, 5.2 to

Table 1. Clinical Characteristics of the Patients

\begin{tabular}{|c|c|c|c|c|}
\hline Characteristic & Total $(n=90)$ & Male $(n=44)$ & Female $(n=46)$ & $P$ value $^{a}$ \\
\hline Age, yr & $28(19-55)$ & $28(19-55)$ & $28.5(19-54)$ & 0.42 \\
\hline Height, cm & $158.1(146.8-182.3)$ & $164.7(146.8-182.3)$ & $152.6(133-166.4)$ & $<0.01$ \\
\hline Weight, kg & $63.5(53.9-103.1)$ & $69.3(53.9-103.1)$ & $59.9(42-93.4)$ & $<0.01$ \\
\hline $\mathrm{BMI}, \mathrm{kg} / \mathrm{m}^{2}$ & $25.0(19.7-41.3)$ & $25.2(19.7-38.5)$ & $24.6(18-41.3)$ & 0.47 \\
\hline Phenotype & & & & 0.28 \\
\hline Salt-wasting & $46(51.1)$ & $20(45.5)$ & $26(56.5)$ & \\
\hline Simple virilizing & $44(48.9)$ & $24(54.5)$ & $20(43.5)$ & \\
\hline Metabolic risk factors & $56(62.2)$ & $33(75)$ & $22(47.8)$ & 0.01 \\
\hline Obesity & $35(38.9)$ & $20(45.5)$ & $15(32.6)$ & 0.21 \\
\hline Hyperglycemia & $25(27.8)$ & $13(29.5)$ & $12(26.1)$ & 0.39 \\
\hline Hypertension & $17(18.9)$ & $11(25)$ & $6(13.0)$ & 0.15 \\
\hline Dyslipidemia & $21(23.3)$ & $12(27.3)$ & $9(19.6)$ & 0.39 \\
\hline \multicolumn{5}{|l|}{ Glucocorticoid type } \\
\hline Hydrocortisone & $2(2.2)$ & $1(2.3)$ & $1(2.2)$ & 0.98 \\
\hline Prednisolone & $90(100)$ & $44(100)$ & $46(100)$ & NA \\
\hline Glucocorticoid-dose/BSA, mg/m²/day & $17.5(5.2-26.7)$ & $16.5(5.2-26.7)$ & $18.9(7.4-24.5)$ & 0.02 \\
\hline Fludrocortisone use & $55(61.1)$ & $28(63.6)$ & $27(58.7)$ & 0.63 \\
\hline $\mathrm{ACTH}^{\mathrm{b}}, \mathrm{pg} / \mathrm{mL}$ & $96.9(2.7-5,030)$ & $107.4(3.3-5,030)$ & $58.9(2.7-726)$ & 0.04 \\
\hline 17-OHP, ng/mL & $34.3(0.6-344)$ & $36.2(1.6-126)$ & $32.6(0.6-344)$ & 0.75 \\
\hline $17-\mathrm{OHP}<10 \mathrm{ng} / \mathrm{mL}$ & $26(28.9)$ & $11(25)$ & $15(32.6)$ & 0.43 \\
\hline Androstenedione $^{\mathrm{b}}, \mathrm{ng} / \mathrm{mL}$ & $1.3(0.1-11.3)$ & $1.5(0.2-9.8)$ & $1.2(0.1-11.3)$ & 0.58 \\
\hline $11 \beta-\mathrm{OHT}^{\mathrm{b}}, \mathrm{ng} / \mathrm{mL}$ & $0.4(0.02-15.1)$ & $0.6(0.02-15.1)$ & $0.4(0.03-4.6)$ & 0.20 \\
\hline $11 \beta-\mathrm{OHA}^{\mathrm{b}}, \mathrm{ng} / \mathrm{mL}$ & $3.2(0.02-51.8)$ & $6.4(0.02-51.8)$ & $3.0(0.02-44.4)$ & 0.21 \\
\hline Preg-S, $\mathrm{ng} / \mathrm{mL}$ & $95.5(2.5-1,201.2)$ & $133.6(12.8-1,045.3)$ & $70.7(2.5-1201.2)$ & 0.20 \\
\hline DHEA-S ${ }^{b}, n g / m L$ & $632(101-5,169)$ & $1,097(248.2-5,017)$ & $403(101-5,169)$ & 0.17 \\
\hline Testosterone $^{\mathrm{b}}, \mathrm{ng} / \mathrm{mL}$ & $1.3(0.08-7.3)$ & $4.8(2.0-7.3)$ & $0.4(0.08-3.7)$ & $<0.01$ \\
\hline Androstenedione/testosterone $\mathrm{e}^{\mathrm{b}}$ & $2.0(0.05-6.3)$ & $2.8(0.9-6.3)$ & $0.3(0.05-2.6)$ & $<0.01$ \\
\hline Plasma renin activity, $\mathrm{ng} / \mathrm{mL}$ & $7.2(0.1-75.2)$ & $6.9(0.1-75.2)$ & $7.1(1.4-49.5)$ & 0.60 \\
\hline
\end{tabular}

Values are expressed as median (range) or number (\%).

BMI, body mass index; NA, not applicable; BSA, body surface area; ACTH, adrenocorticotropic hormone; 17-OHP, 17 $\alpha$-hydroxyprogesterone;

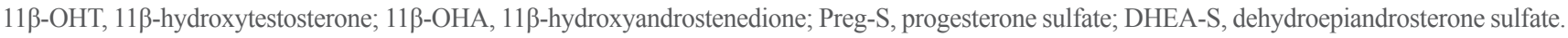

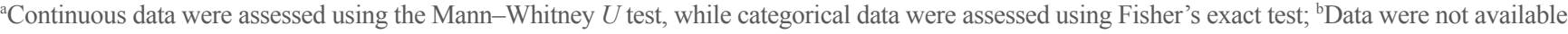

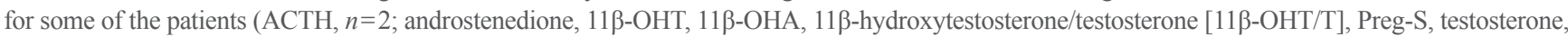
$n=44$; DHEA-S, $n=59$; plasma renin activity, $n=6$ ). 
26.7) and $0.06 \mathrm{mg} / \mathrm{m}^{2}$ (range, 0.03 to 0.40 ), respectively. The ACTH level and androstenedione/T ratio were significantly higher in male than in female patients $(P=0.02$ and $P<0.001$, respectively), while $11 \beta-\mathrm{OHT} / \mathrm{T}$ was significantly higher in female than in male patients $(P<0.001)$. Fifty-six out of 90 patients $(62.2 \%)$ had at least one metabolic morbidity, and the male patients had a significantly higher incidence of metabolic morbidity than female patients ( $75 \%$ vs. $47.8 \%, P=0.01)$. The biochemically well-controlled group comprised 26 patients (28.9\%, 11 men and 15 women), while the poorly-controlled group contained the remaining 64 patients.

\section{Radiologic findings of classical 210HD patients}

Among the 90 patients, 41 (45.6\%) had adrenal hypertrophy, 38 $(42.2 \%)$ had a normal appearance, and $11(12.2 \%)$ had adrenal hypotrophy. In the well-controlled group, one patient showed hypertrophy, while 15 and 10 patients had a normal appearance and hypotrophy of the adrenal glands, respectively. In the poorly-controlled group, 40, 23, and 1 patients showed hypertrophy, normal appearance, and hypotrophy of the adrenal glands, respectively. Twelve patients (13.3\%) had adrenal tumors, which were unilateral in nine patients and bilateral in three patients. Among them, 11 patients showed gross fat in CT images, confirming the presence of myelolipoma. The other patient present- ed with adrenal adenoma. Detailed information on the radiologic findings of $21 \mathrm{OHD}$ patients is summarized in Table 3.

\section{Volumetric and linear evaluation of adrenal glands in 21OHD patients and comparison with healthy controls}

The mean and standard deviation of the right, left, and total adrenal volumes of $21 \mathrm{OHD}$ patients were $8.5 \pm 5.5,9.8 \pm 7.3$, and

Table 3. Radiologic Findings of the Adrenal Gland in Patients with $21 \mathrm{OHD}(n=90)$

\begin{tabular}{lc}
\hline Characteristic & No. $(\%)$ \\
\hline Adrenal morphology & $38(42.2)$ \\
Normal & $41(45.6)$ \\
Hypertrophy & $11(12.2)$ \\
Hypotrophy & $12(13.3)$ \\
Mass & \\
Laterality & $9(10)$ \\
Unilateral & $3(3.3)$ \\
Bilateral & \\
Radiologic diagnosis & $11(12.2)$ \\
Myelolipoma & $1(1.1)$ \\
Adenoma &
\end{tabular}

21OHD, 21-hydroxylase deficiency.

Table 2. Comparison of Patients with Simple Virilizing Type and Salt-Wasting Type

\begin{tabular}{|c|c|c|c|}
\hline Characteristic & Simple virilizing type $(n=44)$ & Salt-wasting type $(n=46)$ & $P$ value ${ }^{\mathrm{a}}$ \\
\hline Glucocorticoid-dose/BSA, mg/m²/day & $17.9(6.7-24.4)$ & $17.3(5.2-26.7)$ & 0.65 \\
\hline Fludrocortisone use & $22(50)$ & $34(73.9)$ & 0.02 \\
\hline $\mathrm{ACTH}^{\mathrm{b}}, \mathrm{pg} / \mathrm{mL}$ & $90.0(3.7-5,030)$ & $97.8(2.7-2,299)$ & 0.80 \\
\hline 17-OHP, ng/mL & $38.7(0.74-344)$ & $34.8(0.6-344)$ & 0.13 \\
\hline $17-\mathrm{OHP}<10 \mathrm{ng} / \mathrm{mL}$ & $10(22.7)$ & $16(34.8)$ & 0.21 \\
\hline Androstenedione ${ }^{\mathrm{b}}, \mathrm{ng} / \mathrm{mL}$ & $1.3(0.2-9.8)$ & $1.2(0.1-11.3)$ & 0.86 \\
\hline $11 \beta-\mathrm{OHT}^{\mathrm{b}}, \mathrm{ng} / \mathrm{mL}$ & $0.4(0.04-7.4)$ & $0.02(0.5-15.1)$ & 0.75 \\
\hline $11 \beta-\mathrm{OHA}^{\mathrm{b}}, \mathrm{ng} / \mathrm{mL}$ & $3.0(0.6-43.6)$ & $0.02(4.8-51.8)$ & 0.88 \\
\hline Preg-S ${ }^{\mathrm{b}}, \mathrm{ng} / \mathrm{mL}$ & $98.5(8.2-946.1)$ & $92.4(2.5-1,201.2)$ & 0.99 \\
\hline DHEA-S ${ }^{\mathrm{b}}, \mathrm{ng} / \mathrm{mL}$ & $811(101-5,169)$ & $675.5(168-4,407)$ & 0.77 \\
\hline Testosterone $^{\mathrm{b}}, \mathrm{ng} / \mathrm{mL}$ & $0.8(0.2-5.4)$ & $1.9(0.08-7.3)$ & 0.93 \\
\hline Plasma renin activity ${ }^{\mathrm{b}}, \mathrm{ng} / \mathrm{mL}$ & $6.0(1.4-29.9)$ & $8.0(0.1-75.2)$ & 0.18 \\
\hline \multicolumn{4}{|c|}{ 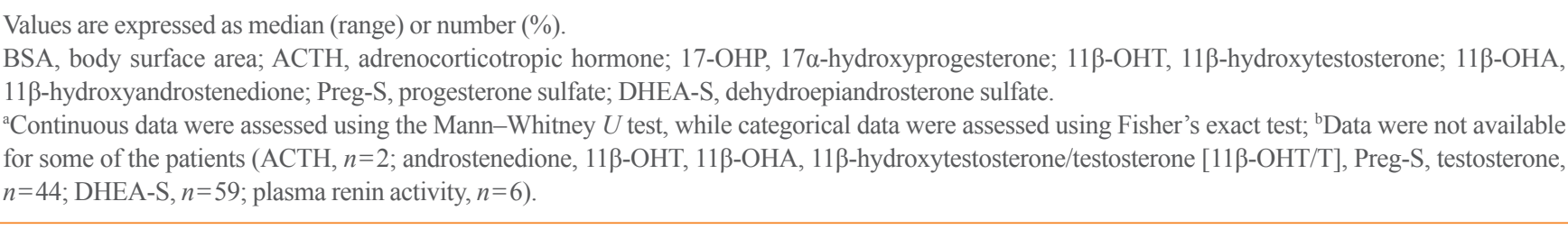 } \\
\hline
\end{tabular}




\begin{tabular}{|c|c|c|c|c|c|c|c|c|c|}
\hline Characteristic & Total & $\begin{array}{c}\text { Men } \\
(n=44)\end{array}$ & $\begin{array}{l}\text { Women } \\
(n=46)\end{array}$ & $P$ value $^{\mathrm{a}}$ & Total & $\begin{array}{c}\text { Men } \\
(n=135)\end{array}$ & $\begin{array}{c}\text { Women } \\
(n=135)\end{array}$ & $P$ value ${ }^{\mathrm{a}}$ & $P$ value ${ }^{\mathrm{b}}$ \\
\hline \multicolumn{10}{|l|}{ Limb width, mm } \\
\hline Right adrenal gland & $4.7 \pm 1.8$ & $4.9 \pm 1.9$ & $4.6 \pm 1.8$ & 0.47 & $3.3 \pm 0.5$ & $3.5 \pm 0.4$ & $3.1 \pm 0.4$ & $<0.001$ & $<0.001$ \\
\hline Average of both adrenal glands & $4.7 \pm 1.9$ & $4.8 \pm 2.0$ & $4.5 \pm 1.8$ & 0.41 & $3.3 \pm 0.5$ & $3.5 \pm 0.5$ & $3.1 \pm 0.5$ & $<0.001$ & $<0.001$ \\
\hline \multicolumn{10}{|l|}{ Volume, mL } \\
\hline Right adrenal gland & $8.5 \pm 5.6$ & $8.7 \pm 5.5$ & $8.3 \pm 5.7$ & 0.80 & $3.5 \pm 1.0$ & $4.1 \pm 0.9$ & $3.0 \pm 0.8$ & $<0.001$ & $<0.001$ \\
\hline Left adrenal gland & $9.9 \pm 7.4$ & $10.8 \pm 8.4$ & $9.0 \pm 6.3$ & 0.26 & $3.6 \pm 1.1$ & $4.3 \pm 1.0$ & $2.9 \pm 0.6$ & $<0.001$ & $<0.001$ \\
\hline Both adrenal glands & $18.4 \pm 12.4$ & $19.4 \pm 13.1$ & $17.4 \pm 11.7$ & 0.43 & $7.1 \pm 2.0$ & $8.4 \pm 1.9$ & $5.9 \pm 1.4$ & $<0.001$ & $<0.001$ \\
\hline
\end{tabular}

$18.2 \pm 12.2 \mathrm{~mL}$, respectively. These values were all significantly larger than in healthy controls $(3.5 \pm 1.0,3.6 \pm 1.1,7.1 \pm 2.0 \mathrm{~mL}$, $P<0.001$ for all). The right, left, and average adrenal width were also significantly higher in $21 \mathrm{OHD}$ patients than in normal controls $(4.7 \pm 1.8 \mathrm{~mm}$ vs. $3.3 \pm 0.5 \mathrm{~mm}, 4.6 \pm 2.0 \mathrm{~mm}$ vs. $3.3 \pm 0.5$ $\mathrm{mm}, 4.7 \pm 1.9 \mathrm{~mm}$ vs. $3.3 \pm 0.5 \mathrm{~mm}, P<0.001$ for all). All limb width and volume parameters were significantly higher in men than in women among the healthy controls $(P<0.001$ for all); however, there was no statistically significant difference between men and women with $21 \mathrm{OHD}(P>0.05$ for all). We obtained an area under the curve (AUC) of 0.85 for classifying patients with $21 \mathrm{OHD}(P<0.001)$ with a sensitivity of $81.1 \%$ and specificity of $90 \%$ at a cut-off value of $9.1 \mathrm{~mL}$. Table 4 presents detailed information on linear and volumetric parameters.

\section{Subgroup analysis of adrenal volume in $210 H D$ patients}

The adrenal volume between patients with salt-wasting $21 \mathrm{OHD}$ and those with the simple virilizing type was not significantly different $(17.9 \pm 13.9 \mathrm{~mL}$ vs. $18.4 \pm 8.9 \mathrm{~mL}, P=0.31)$. Patients with irregular menstruation showed significantly larger adrenal volumes than those with regular menstruation $(21.0 \pm 12.9 \mathrm{~mL}$ vs. $12.7 \pm 8.5 \mathrm{~mL}, P=0.009$ ). In addition, patients with adrenal tumors had significantly larger adrenal volumes than those without any masses $(31.8 \pm 16.1 \mathrm{~mL}$ vs. $15.7 \pm 9.5 \mathrm{~mL}, P=0.025)$.

\section{Correlation analysis of adrenal volume and width with hormonal status}

Both of the plasma levels of 17-OHP and androstenedione were significantly different among groups according to adrenal morphology (hypertrophy, normal appearance, and hypotrophy; $P<0.001$ and $P<0.02$, respectively). Patients with adrenal hypertrophy showed the highest 17-OHP and androstenedione levels (median, $49.9 \mathrm{ng} / \mathrm{mL}$ [interquartile range (IQR), 22.2 to $108.7]$ and $2.6 \mathrm{ng} / \mathrm{mL}$ [IQR, 1.0 to 5.0], respectively), followed by those with normal adrenal glands $(32.1 \mathrm{ng} / \mathrm{mL}$ [IQR, 5.1 to $58.3]$ and $1.1 \mathrm{ng} / \mathrm{mL}$ [IQR, 0.5 to 1.6$]$ ) and those with adrenal hypotrophy (3.6 ng/mL [IQR, 2.8 to 8.9 ] and $0.4 \mathrm{ng} / \mathrm{mL}$ [IQR, 0.2 to 1.1$]$ ) (Fig. 2).

The total adrenal volume correlated positively with $\mathrm{ACTH}$, 17-OHP, DHEA-S, androstenedione, 11 $\beta-O H T, 11 \beta-O H A$, and Preg-S in both male and female patients $(r=0.43-0.94, P<0.05$ for all). Positive correlations were found for $11 \beta-\mathrm{OHT} / \mathrm{T}$ and plasma renin activity in male patients $(r=0.49-0.70, P<0.05$ for both) and for testosterone in female patients $(r=0.70, P<0.001)$ (Fig. 3). Adrenal width correlated positively with ACTH, 17OHP, 11ß-OHT, 11ß-OHT/T, Preg-S, DHEA-S in both male and female patients $(r=0.31-0.95, P<0.05$ for all). The adrenal width showed positive correlations with androstenedione, $11 \beta$-OHA, plasma renin activity only in male $(r=0.43-0.81$, $P<0.05$ for all), and showed positive correlation with testosterone only in female $(r=0.44, P=0.03)$. Table 5 presents detailed information on the correlation analysis.

The daily glucocorticoid dose/BSA correlated negatively with adrenal volume ( $r=-0.24, P=0.02)$, but showed no significant correlation with adrenal width $(r=-0.14, P=0.19)$. The daily fludrocortisone dose/BSA did not show significant correlations 

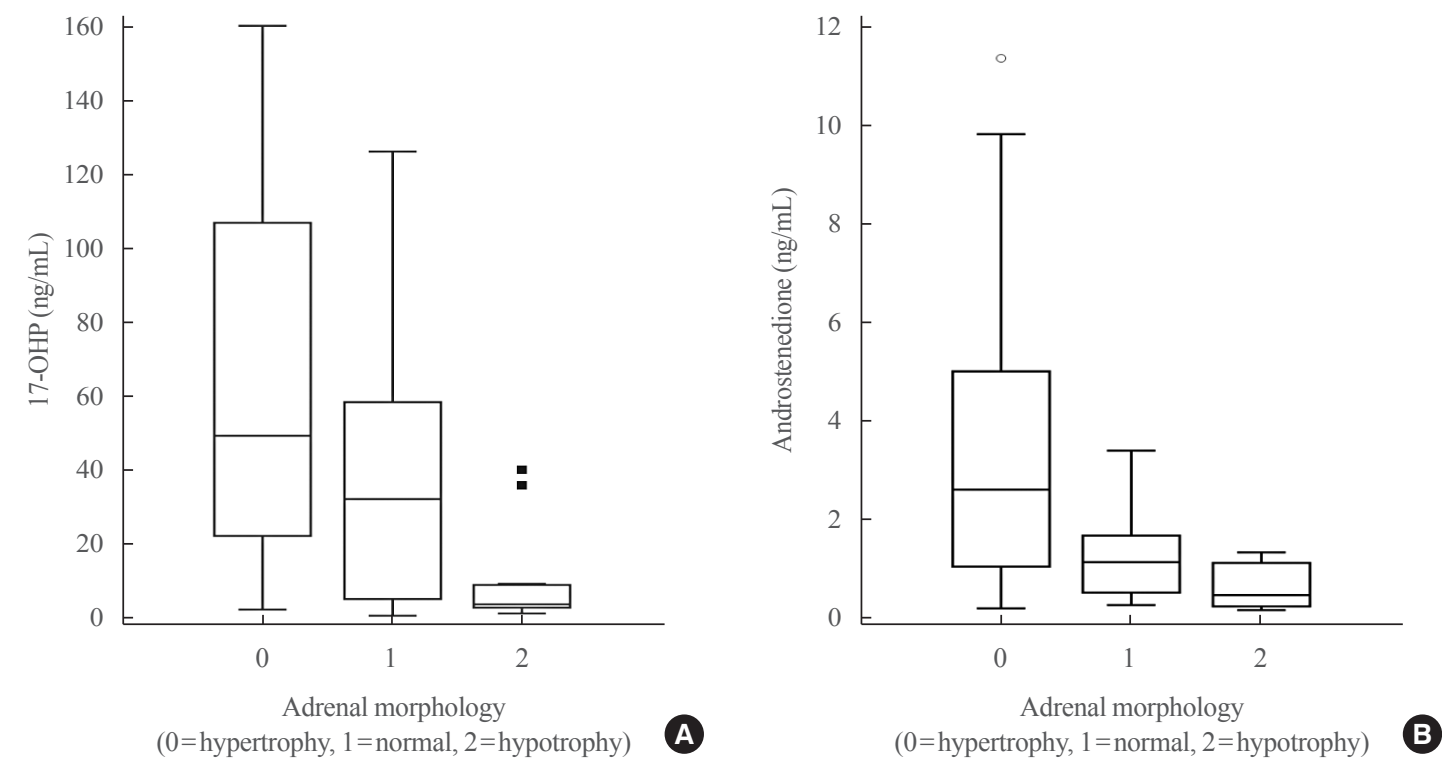

Fig. 2. Plasma levels of (A) 17 $\alpha$-hydroxyprogesterone (17-OHP) and (B) androstenedione according to the adrenal morphology. Patients with adrenal hypertrophy showed the highest 17-OHP and androstenedione levels, followed by those with normal adrenal glands and adrenal hypotrophy.

Table 5. Correlations of Adrenal Volume and Width with Hormonal Status in Patients with 21OHD

\begin{tabular}{|c|c|c|c|c|c|c|c|c|c|c|c|c|}
\hline \multirow{3}{*}{ Variable } & \multicolumn{6}{|c|}{ Adrenal volume } & \multicolumn{6}{|c|}{ Adrenal width } \\
\hline & \multicolumn{3}{|c|}{ Men } & \multicolumn{3}{|c|}{ Women } & \multicolumn{3}{|c|}{ Men } & \multicolumn{3}{|c|}{ Women } \\
\hline & No. & $r$ & $P$ value $^{\mathrm{a}}$ & No. & $r$ & $P$ value ${ }^{a}$ & No. & $r$ & $P$ value $^{a}$ & No. & $r$ & $P$ value $^{a}$ \\
\hline ACTH & 43 & 0.523 & $<0.001$ & 45 & 0.434 & 0.003 & 43 & 0.326 & 0.03 & 45 & 0.407 & 0.006 \\
\hline 17-OHP & 44 & 0.644 & $<0.001$ & 46 & 0.578 & $<0.001$ & 44 & 0.627 & $<0.001$ & 46 & 0.460 & 0.001 \\
\hline Androstenedione & 20 & 0.592 & 0.006 & 26 & 0.610 & $<0.001$ & 20 & 0.654 & 0.002 & 26 & 0.319 & 0.112 \\
\hline $11 \beta-\mathrm{OHT}$ & 20 & 0.681 & 0.001 & 26 & 0.643 & $<0.001$ & 20 & 0.827 & $<0.001$ & 26 & 0.558 & 0.003 \\
\hline $11 \beta-\mathrm{OHA}$ & 20 & 0.711 & $<0.001$ & 26 & 0.658 & $<0.001$ & 20 & 0.807 & $<0.001$ & 26 & 0.303 & 0.133 \\
\hline $11 \beta-\mathrm{OHT} / \mathrm{T}$ & 20 & 0.700 & $<0.001$ & 26 & 0.181 & 0.377 & 20 & 0.836 & $<0.001$ & 26 & 0.454 & 0.020 \\
\hline Preg-S & 20 & 0.637 & 0.003 & 26 & 0.606 & 0.001 & 20 & 0.671 & 0.001 & 26 & 0.391 & 0.048 \\
\hline DHEA-S & 10 & 0.941 & $<0.001$ & 22 & 0.557 & 0.007 & 10 & 0.953 & $<0.001$ & 22 & 0.617 & 0.002 \\
\hline Testosterone & 20 & -0.230 & 0.329 & 26 & 0.696 & $<0.001$ & 20 & -0.209 & 0.376 & 26 & 0.438 & 0.025 \\
\hline Plasma renin activity & 39 & 0.488 & 0.002 & 45 & 0.126 & 0.409 & 39 & 0.431 & 0.006 & 45 & 0.102 & 0.507 \\
\hline
\end{tabular}

21OHD, 21-hydroxylase deficiency; ACTH, adrenocorticotropic hormone; 17-OHP, 17 $\alpha$-hydroxyprogesterone; 11 $\beta$-OHT, 11 beta-hydroxytestosterone;

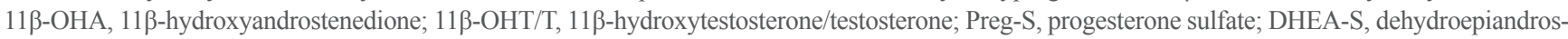
terone sulfate.

${ }^{a}$ Correlations were evaluated using the Spearman correlation coefficient. Non-normally distributed variables (adrenal volume and all biochemical parameters) were log-transformed.

with adrenal volume or width $(P>0.05$ in both).

\section{Diagnostic performance of adrenal volume and width for the identifying $210 \mathrm{HD}$ patients with well-controlled status and metabolic morbidity}

The total adrenal volume and width yielded AUCs of 0.87 (95\% confidence interval [CI], 0.78 to 0.93$)$ and 0.82 (95\% CI, 0.72 to 0.89 ), respectively, for predicting the biochemically wellcontrolled group $(P<0.001$ for both) (Fig. 4). We could achieve a sensitivity of $73.1 \%$ and specificity of $90.6 \%$ using a cut-off value of $10.7 \mathrm{~mL}$ of adrenal volume. Using a cutoff value of 4.0 $\mathrm{mm}$ of adrenal width, a sensitivity of $80.8 \%$ and specificity of 

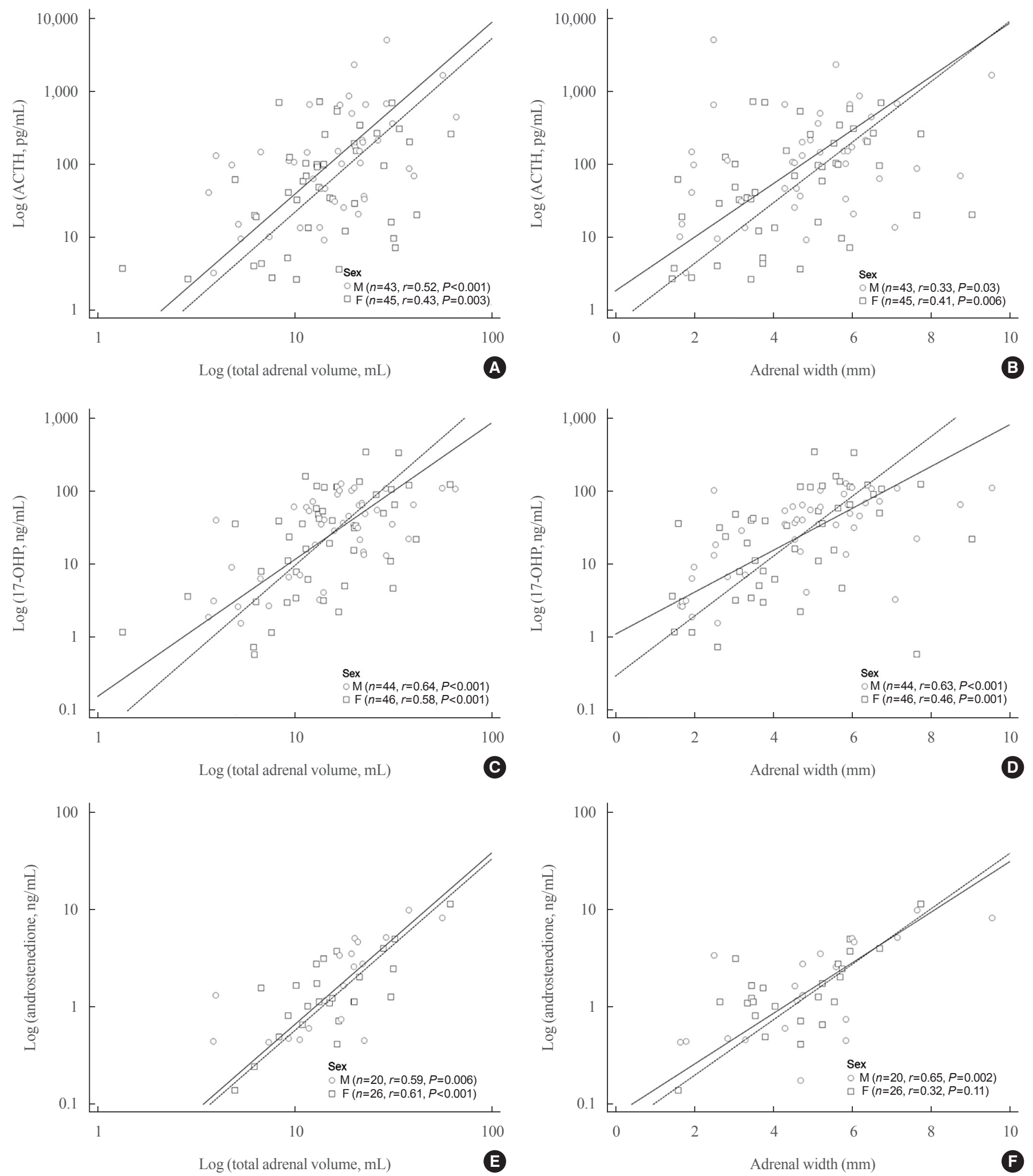

Fig. 3. Correlations between total adrenal volume and hormonal status and adrenal width and hormonal status. Both total adrenal volume and adrenal width correlated positively with (A, B) adrenocorticotropic hormone (ACTH) and (C, D) 17a-hydroxyprogesterone (17-OHP) levels regardless of sex. (E, F) Androstenedione levels correlated positively with adrenal volume in both male and female patients, and with adrenal width in male patients. 

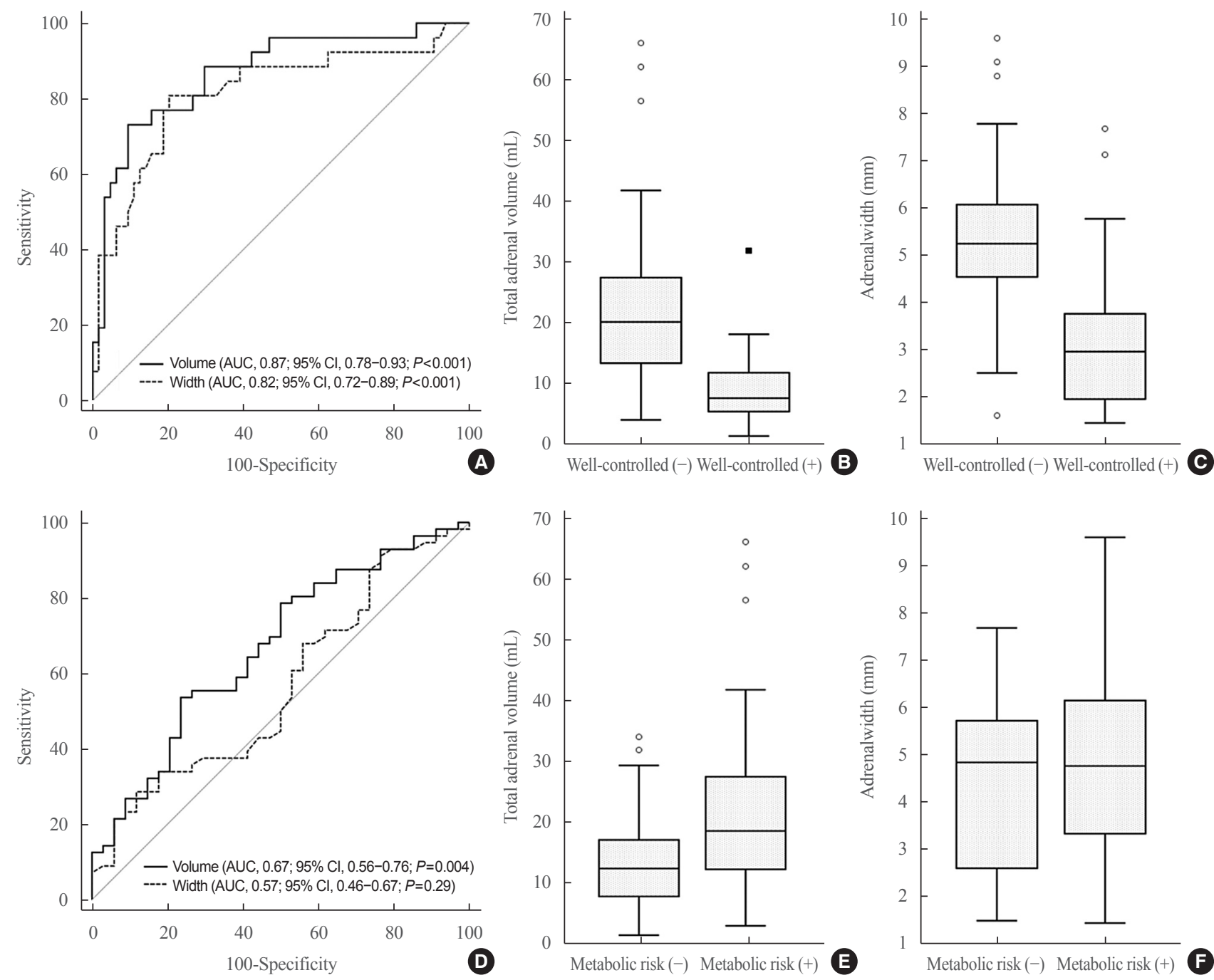

Fig. 4. Receiver operating characteristic curves and box-and-whisker diagrams of adrenal volume and width for classifying well-controlled patients $(\mathrm{A}, \mathrm{B}, \mathrm{C})$ and patients with at least one metabolic morbidity (D, E, F), respectively. AUC, area under the curve; CI, confidence interval.

$79.7 \%$ were obtained. The AUCs of adrenal volume and width showed no significant differences $(P=0.24)$.

The total adrenal volume resulted in an AUC of 0.67 (95\% CI, 0.56 to 0.76 ) for predicting patients with one or more metabolic morbidity $(P=0.004)$. Using a cut-off value of $17 \mathrm{~mL}$, a sensitivity of $55.4 \%$ and specificity of $76.5 \%$ were obtained. Adrenal width showed no significant diagnostic value for predicting the patients with a metabolic morbidity (AUC, 0.57 ; $95 \% \mathrm{CI}, 0.46$ to $0.67 ; P=0.29)$. The AUC of adrenal volume was significantly higher than that of adrenal width $(P=0.03)$.

\section{Correlation analysis between hormonal status and adrenal tumors}

Patients with adrenal tumors showed significantly higher ACTH,
$11 \beta-\mathrm{OHA}$, and Preg-S levels than those without adrenal tumors $(P<0.05$ for all). Table 6 presents detailed information. The total volume of adrenal tumors did not show a significant correlation with any hormone levels ( $P>0.05$ for all).

\section{Comparison of body composition between well-controlled and poorly-controlled patients}

The BMI was significantly higher in the poorly-controlled group than in the well-controlled group $(P=0.006)$. The poorlycontrolled group showed a significantly higher area of subcutaneous fat and total abdominal fat in the L3 level than the wellcontrolled group ( $P=0.04$ in both). The visceral fat and muscle areas did not differ significantly between the two groups $(P>0.05)$. The waist circumference was significantly higher in 
Table 6. Comparisons of Hormonal Status between Patients with and without Adrenal Tumors

\begin{tabular}{lccc}
\hline Biochemical parameters $^{\mathrm{a}}$ & Adrenal tumor $(+)(n=12)$ & Adrenal tumor $(-)(n=78)$ & $P$ value $^{\mathrm{b}}$ \\
\hline ACTH & $259(100.5-686.0)$ & $87.7(18.6-195.7)$ & 0.02 \\
$17-$ OHP & $49.2(25.2-95.5)$ & $31.6(6.4-65.0)$ & 0.25 \\
Androstenedione & $3.3(1.7-7.6)$ & $1.2(0.5-2.8)$ & 0.15 \\
$11 \beta-$ OHT & $2.3(1.0-3.8)$ & $0.4(1.5-0.9)$ & 0.07 \\
$11 \beta-O H A$ & $23.8(12.9-34.4)$ & $3.0(0.7-7.3)$ & 0.03 \\
$11 \beta-O H T / T$ & $1.4(1.0-1.5)$ & $0.7(0.1-1.0)$ & 0.12 \\
Preg-S & $807.3(399-1,052)$ & $82.2(31-246)$ & 0.03 \\
DHEA-S & 632 & $675.5(346-1,721)$ & 0.92 \\
Testosterone & $2.1(1.1-3.0)$ & $1.1(0.3-4.8)$ & 0.87 \\
Plasma renin activity & $11.0(7.7-14.8)$ & $6.9(4.3-12.5)$ & 0.14 \\
\hline
\end{tabular}

Values are expressed as median (range).

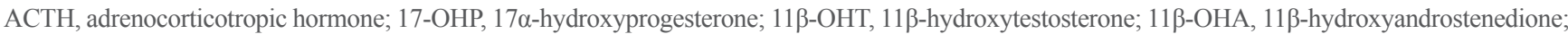
$11 \beta-O H T / T, 11 \beta$-hydroxyandrostenedione/testosterone; Preg-S, progesterone sulfate; DHEA-S, dehydroepiandrosterone sulfate.

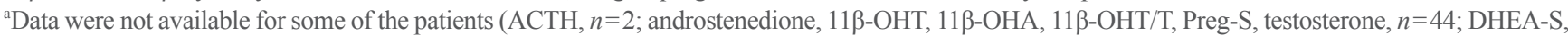
$n=59$; plasma renin activity, $n=6$ ); ${ }^{\mathrm{b}}$ Continuous data were compared using the Mann-Whitney $U$ test.

Table 7. Comparisons of Body Composition, Adrenal Morphology, and Biochemical Parameters between Well-Controlled and PoorlyControlled Patients

\begin{tabular}{|c|c|c|c|}
\hline Parameter & Well-controlled $(n=26)$ & Poorly-controlled $(n=64)$ & $P$ value ${ }^{a}$ \\
\hline BMI, $\mathrm{kg} / \mathrm{m}^{2}$ & $24.3 \pm 4.7$ & $26.9 \pm 4.9$ & $<0.01$ \\
\hline Subcutaneous fat area, $\mathrm{cm}^{2}$ & $163.7 \pm 74.7$ & $202.3 \pm 81.9$ & 0.04 \\
\hline Visceral fat area, $\mathrm{cm}^{2}$ & $88.1 \pm 47.3$ & $110.9 \pm 63.3$ & 0.10 \\
\hline Total abdominal fat area, $\mathrm{cm}^{2}$ & $251.8 \pm 113.5$ & $313.2 \pm 131.1$ & 0.04 \\
\hline Muscle area, $\mathrm{cm}^{2}$ & $116.0 \pm 23.4$ & $126.3 \pm 31.5$ & 0.14 \\
\hline Waist circumference, $\mathrm{cm}$ & $86.9 \pm 11.0$ & $94.8 \pm 15.2$ & 0.02 \\
\hline Adrenal volume, $\mathrm{mL}$ & $9.4 \pm 6.2$ & $21.6 \pm 12.3$ & $<0.01$ \\
\hline Adrenal width, mm & $3.2 \pm 1.7$ & $5.2 \pm 1.6$ & $<0.01$ \\
\hline $\mathrm{ACTH}^{\mathrm{b}}$ & $11.3(2.7-148.8)$ & $139.6(7.4-5,030)$ & $<0.01$ \\
\hline 17-OHP & $3.3(0.6-9.2)$ & $51.6(11.1-344)$ & $<0.01$ \\
\hline Androstenedione $^{\mathrm{b}}$ & $0.7(0.2-3.1)$ & $1.3(0.1-11.3)$ & 0.06 \\
\hline $11 \beta-\mathrm{OHT}^{\mathrm{b}}$ & $0.09(0.02-0.8)$ & $0.7(0.02-15.1)$ & $<0.01$ \\
\hline $11 \beta-\mathrm{OHA}{ }^{\mathrm{b}}$ & $0.6(0.02-5.5)$ & $5.0(0.02-51.8)$ & $<0.01$ \\
\hline $11 \beta-\mathrm{OHT} / \mathrm{T}^{\mathrm{b}}$ & $0.1(0.003-1.5)$ & $0.8(0.007-2.8)$ & 0.02 \\
\hline Preg-S ${ }^{b}$ & $43.8(12.8-320.8)$ & $149.2(2.5-1,201)$ & 0.04 \\
\hline DHEA-S ${ }^{b}$ & $387(101-2,016)$ & $1,328(228-5,169)$ & 0.04 \\
\hline Testosterone $^{\mathrm{b}}$ & $1.0(0.1-6.8)$ & $1.9(0.08-7.3)$ & 0.98 \\
\hline Plasma renin activity ${ }^{\mathrm{b}}$ & $6.6(0.1-29.9)$ & $7.8(1.4-75.2)$ & 0.45 \\
\hline
\end{tabular}

Values are expressed as mean \pm standard deviations or median (range).

BMI, body mass index; ACTH, adrenocorticotropic hormone; 17-OHP, $17 \alpha$-hydroxyprogesterone; 11 $\beta$-OHT, $11 \beta$-hydroxytestosterone; 11 $\beta$-OHA,

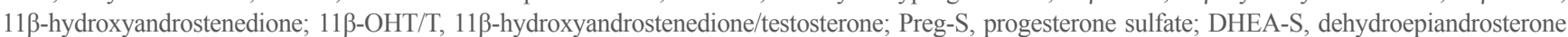
sulfate.

${ }^{a}$ Data were compared using the independent $t$ test for normally distributed variables (all of computed tomography parameters) or the Mann-Whitney $U$ test

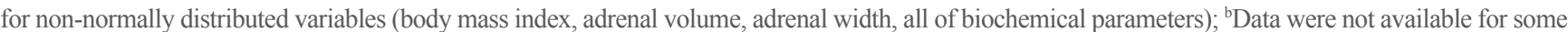
of the patients (ACTH, $n=2$; androstenedione, $11 \beta-\mathrm{OHT}, 11 \beta-\mathrm{OHA}, 11 \beta-\mathrm{OHT} / \mathrm{T}$, Preg-S, testosterone, $n=44$; DHEA-S, $n=59$; plasma renin activity, $n=6$ ). 
the poorly-controlled group than in the well-controlled group $(P=0.02)$. Table 7 summarizes detailed information on body composition.

\section{Interobserver agreement}

The interobserver agreement for adrenal width measurements was $0.689,0.598$, and 0.685 ( $P<0.001$ for all) for the right, left, and average adrenal widths, respectively. All adrenal volume parameters, including the right, left, and both adrenal glands, showed excellent agreement (ICC, 0.874, 0.906, 0.888, respectively; $P<0.001$ for all).

\section{DISCUSSION}

Our study demonstrated that the total adrenal volume and adrenal width measured by abdominal CT reflected the extent of disease control in patients with 21OHD. Thus, adrenal volume and width can be useful for identifying $210 H D$ patients with well-controlled status or at least one metabolic morbidity. To our knowledge, this is the first study to predict the disease control status of $21 \mathrm{OHD}$ patients using adrenal volume and width with optimal cut-off values.

Reisch et al. [12] first evaluated the association between adrenal volume and hormonal control in patients with 21OHD. They found that adrenal volume correlated positively with androstenedione, 17-OHP in serum, and pregnanetriol in urine. However, the number of patients included in the study was small $(n=26)$, and all of them were male. This might be the reason why ACTH, plasma renin activity, and DHEA-S did not show significant correlations with adrenal volume in their study, unlike the findings of the current study. Adina et al. analyzed correlations of a mass-spectrometry panel of 23 steroids with disease control status, including adrenal volume, and found that 11-oxygenated androgens could serve as clinically useful biomarkers [11]. However, these hormone measurements are not currently available in clinical practice, limiting their clinical usefulness. Above all, those two studies did not suggest a specific cut-off value of adrenal volume for evaluating the disease control status. This study is the first to set cut-off volumes to classify well-controlled patients and patients with at least one metabolic morbidity (10.7 and $17 \mathrm{~mL}$, respectively), with acceptable diagnostic accuracy (AUC, 0.87 and 0.67, respectively).

A remarkable finding of our study is that we found the clinical significance of adrenal gland hypotrophy in patients with 21OHD. Secondary adrenal hypoplasia is known to result from ACTH suppression. Surprisingly, 11 patients (12.2\%) showed diffuse hypotrophy of the adrenal gland, in contrast to the typical adrenal morphology of patients with 21OHD. The 17-OHP and androstenedione levels were lower in patients with adrenal hypotrophy than in those with normal adrenal glands and adrenal hypertrophy. Of particular note, half of the patients with adrenal hypotrophy showed normal values of 17-OHP, which suggests overtreatment [4]. One patient showed adrenal hypotrophy, but had a high 17-OHP level (33.1 ng/mL). Because the adrenal morphology is thought to be affected by long-term hormonal status, it would not reflect very recent hormonal changes. Therefore, the adrenal morphology may not perfectly represent the hormonal state at the time of the CT scan. Nevertheless, when we detect adrenal gland hypotrophy in patients with $210 H D$, we should beware of overtreatment.

Accurate volumetric measurement of the adrenal gland is crucial because of its high interobserver variability owing to its small volume [17]. CT is considered the gold standard for volume measurement of organs in vivo. Magnetic resonance imaging (MRI) can also produce high-resolution volume data; however, magnetic field inhomogeneity combined with chemical shift artifacts can result in spatial inhomogeneity. We used multi-detector CT with thin slices of $3 \mathrm{~mm}$ to measure the adrenal volume. Our data are expected to be more accurate than those of other studies that measured the adrenal volume on CT with thick slices of $\geq 5 \mathrm{~mm}$ or those conducted with MRI $[8,12,18]$.

We performed both volumetric and linear assessments of the adrenal gland to compare the diagnostic performance. We hypothesized that the complex shape of the adrenal glands could complicate the measurement of the adrenal width in two-dimensional CT images. As we expected, the reproducibility of adrenal width (good agreement, ICC 0.685) was inferior to that of adrenal volume (excellent agreement, ICC 0.888). However, adrenal width showed a good correlation with biochemical parameters. Furthermore, it showed good diagnostic performance for predicting biochemically well-controlled patients (AUC, 0.82). Adrenal width can be easily applied in real clinical practice considering its rapidity of measurement.

Our study demonstrated the prevalence of adrenal masses in adult patients with classic $210 \mathrm{HD}$ who were on medication. Approximately $13.3 \%$ of the patients had adrenal tumors, which is much lower than the value reported in a previous study [19]. Moreover, only one patient $(1.1 \%)$ had adenoma in our study, while most tumors were described as "silent adenomas" in a previous study [19]. This discrepancy might be attributed to differences in image interpretation. Adrenal hyperplasia is a major 
condition that is often falsely diagnosed as adenoma due to a significant overlap in imaging findings [20,21]. A majority of patients with $21 \mathrm{OHD}$ who were considered to have adenomas in previous studies may actually have had adrenal hyperplasia. In addition, all the patients in the current study with adrenal tumors, except for one, had myelolipomas. Some patients with untreated 21OHD with very high serum ACTH levels occasionally demonstrate large myelolipomas [22,23]. Chronic ACTH stimulation might play an important role in myelolipoma development [24]. In concordance with these findings, patients with adrenal tumors showed higher ACTH levels than those without tumors in our study. This finding can be interpreted as indicating that adrenal imaging should be considered in patients with $21 \mathrm{OHD}$ with high ACTH levels to identify adrenal incidentalomas, especially myelolipomas.

It is well known that patients with 21OHD have a higher prevalence of metabolic morbidities than the normal population [3,25]. Adrenal volume was useful in identifying 21OHD patients with at least one metabolic morbidity (AUC, 0.67). We also found that total abdominal fat area and waist circumference were significantly different according to patients' hormonal control status.

Our study had several limitations. First, this study was performed retrospectively at a single center; thus, there may have been selection bias. Second, the hormones examined were different for each patient depending on the clinician's determination. In addition, single measurement results of the hormones were analyzed. In particular, patients with $210 H D$ were classified into well-controlled and poorly-controlled groups according to a single measurement of 17-OHP levels. Third, not all patients in our cohort were genetically confirmed to have classical 21OHD. However, all patients showed typical hormone abnormalities and a clinical course consistent with classical 21OHD. Finally, measuring adrenal volume is time-consuming and laborious compared with measuring adrenal width. For application in clinical practice, automatic or semi-automatic volumetric assessment of the adrenal gland is warranted.

In conclusion, adrenal volume and width were associated with hormonal status in patients with $21 \mathrm{OHD}$ and showed good diagnostic performance in identifying well-controlled patients and patients with at least one metabolic morbidity. Given the lifetime duration of the disease course, both adrenal volume and width are reliable quantitative parameters for monitoring patients with classical 21OHD.

\section{CONFLICTS OF INTEREST}

No potential conflict of interest relevant to this article was reported.

\section{AUTHOR CONTRIBUTIONS}

Conception or design: T.M.K., J.H.K., H.N.J., M.H.C., J.Y.C., S.Y.K. Acquisition, analysis, or interpretation of data: T.M.K., J.H.K., H.N.J., M.H.C., J.Y.C., S.Y.K. Drafting the work or revising: T.M.K., J.H.K., H.N.J., M.H.C., J.Y.C., S.Y.K. Final approval of the manuscript: T.M.K., J.H.K., H.N.J., M.H.C., J.Y.C., S.Y.K.

\section{ORCID}

Taek Min Kim https://orcid.org/0000-0001-6915-8795

Jung Hee Kim https://orcid.org/0000-0003-1932-0234

Sang Youn Kim https://orcid.org/0000-0003-4038-7345

\section{REFERENCES}

1. Merke DP, Bornstein SR. Congenital adrenal hyperplasia. Lancet 2005;365:2125-36.

2. Charmandari E, Chrousos GP. Metabolic syndrome manifestations in classic congenital adrenal hyperplasia: do they predispose to atherosclerotic cardiovascular disease and secondary polycystic ovary syndrome? Ann N Y Acad Sci 2006;1083:37-53.

3. Torky A, Sinaii N, Jha S, Desai J, El-Maouche D, Mallappa A, et al. Cardiovascular disease risk factors and metabolic morbidity in a longitudinal study of congenital adrenal hyperplasia. J Clin Endocrinol Metab 2021;106:e5247-57.

4. Speiser PW, Arlt W, Auchus RJ, Baskin LS, Conway GS, Merke DP, et al. Congenital adrenal hyperplasia due to steroid 21-hydroxylase deficiency: an Endocrine Society clinical practice guideline. J Clin Endocrinol Metab 2018;103: 4043-88.

5. Chrysostomou PP, Lodish MB, Turkbey EB, Papadakis GZ, Stratakis CA. Use of 3-dimensional volumetric modeling of adrenal gland size in patients with primary pigmented nodular adrenocortical disease. Horm Metab Res 2016;48:242-6.

6. Degenhart C, Schneller J, Osswald A, Pallauf A, Riester A, Reiser MF, et al. Volumetric and densitometric evaluation of the adrenal glands in patients with primary aldosteronism. Clin Endocrinol (Oxf) 2017;86:325-31. 
7. Godoy-Matos AF, Vieira AR, Moreira RO, Coutinho WF, Carraro LM, Moreira DM, et al. The potential role of increased adrenal volume in the pathophysiology of obesityrelated type 2 diabetes. J Endocrinol Invest 2006;29:159-63.

8. Vincent JM, Morrison ID, Armstrong P, Reznek RH. The size of normal adrenal glands on computed tomography. Clin Radiol 1994;49:453-5.

9. Wang X, Jin ZY, Xue HD, Liu W, Sun H, Chen Y, et al. Evaluation of normal adrenal gland volume by 64 -slice CT. Chin Med Sci J 2013;27:220-4.

10. Auchus RJ, Arlt W. Approach to the patient: the adult with congenital adrenal hyperplasia. J Clin Endocrinol Metab 2013;98:2645-55.

11. Turcu AF, Mallappa A, Elman MS, Avila NA, Marko J, Rao $\mathrm{H}$, et al. 11-Oxygenated androgens are biomarkers of adrenal volume and testicular adrenal rest tumors in 21-hydroxylase deficiency. J Clin Endocrinol Metab 2017;102:2701-10.

12. Reisch N, Scherr M, Flade L, Bidlingmaier M, Schwarz HP, Muller-Lisse U, et al. Total adrenal volume but not testicular adrenal rest tumor volume is associated with hormonal control in patients with 21-hydroxylase deficiency. J Clin Endocrinol Metab 2010;95:2065-72.

13. Rivkees SA, Crawford JD. Dexamethasone treatment of virilizing congenital adrenal hyperplasia: the ability to achieve normal growth. Pediatrics 2000;106:767-73.

14. Alberti KG, Eckel RH, Grundy SM, Zimmet PZ, Cleeman JI, Donato KA, et al. Harmonizing the metabolic syndrome: a joint interim statement of the International Diabetes Federation Task Force on Epidemiology and Prevention; National Heart, Lung, and Blood Institute; American Heart Association; World Heart Federation; International Atherosclerosis Society; and International Association for the Study of Obesity. Circulation 2009;120:1640-5.

15. Lee YS, Hong N, Witanto JN, Choi YR, Park J, Decazes P, et al. Deep neural network for automatic volumetric segmentation of whole-body CT images for body composition assessment. Clin Nutr 2021;40:5038-46.
16. Lee C, Kim JH, Moon SJ, Shim J, Kim HI, Choi MH. Selective LC-MRM/SIM-MS based profiling of adrenal steroids reveals metabolic signatures of $17 \alpha$-hydroxylase deficiency. J Steroid Biochem Mol Biol 2020;198:105615.

17. Geraghty EM, Boone JM, McGahan JP, Jain K. Normal organ volume assessment from abdominal CT. Abdom Imaging 2004;29:482-90.

18. Schneller J, Reiser M, Beuschlein F, Osswald A, Pallauf A, Riester A, et al. Linear and volumetric evaluation of the adrenal gland: MDCT-based measurements of the adrenals. Acad Radiol 2014;21:1465-74.

19. Jaresch S, Kornely E, Kley HK, Schlaghecke R. Adrenal incidentaloma and patients with homozygous or heterozygous congenital adrenal hyperplasia. J Clin Endocrinol Metab 1992;74:685-9.

20. Park BK, Kim B, Ko K, Jeong SY, Kwon GY. Adrenal masses falsely diagnosed as adenomas on unenhanced and delayed contrast-enhanced computed tomography: pathological correlation. Eur Radiol 2006;16:642-7.

21. Park SY, Park BK, Park JJ, Kim CK. Differentiation of adrenal hyperplasia from adenoma by use of CT densitometry and percentage washout. AJR Am J Roentgenol 2016;206: 106-12.

22. German-Mena E, Zibari GB, Levine SN. Adrenal myelolipomas in patients with congenital adrenal hyperplasia: review of the literature and a case report. Endocr Pract 2011; 17:441-7.

23. McGeoch SC, Olson S, Krukowski ZH, Bevan JS. Giant bilateral myelolipomas in a man with congenital adrenal hyperplasia. J Clin Endocrinol Metab 2012;97:343-4.

24. Selye H, Stone H. Hormonally induced transformation of adrenal into myeloid tissue. Am J Pathol 1950;26:211-33.

25. Falhammar H, Filipsson Nystrom H, Wedell A, Thoren M. Cardiovascular risk, metabolic profile, and body composition in adult males with congenital adrenal hyperplasia due to 21-hydroxylase deficiency. Eur J Endocrinol 2011;164:28593. 